WellBeing International

WBI Studies Repository

1998

\title{
A demanding task: using economic techniques to assess animal priorities. A reply to Mason et al.
}

\author{
C. M. Sherwin \\ University of Bristol \\ C. J. Nicol \\ University of Bristol
}

Follow this and additional works at: https://www.wellbeingintlstudiesrepository.org/ecoawel

Part of the Animal Studies Commons, Other Anthropology Commons, and the Other Economics

Commons

\section{Recommended Citation}

Mason, G., Mcfarland, D., \& Garner, J. (1998). A demanding task: using economic techniques to assess animal priorities.

This material is brought to you for free and open access by WellBeing International. It has been accepted for inclusion by an authorized administrator of the WBI Studies Repository. For more information, please contact wbisr-info@wellbeingintl.org.

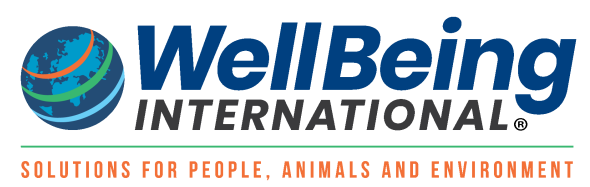




\title{
A demanding task: using economic techniques to assess animal priorities. $A$ reply to $M$ ason et al.
}

\author{
C. M. SHERWIN \& C. J. NICOL \\ Division of A nimal $\mathrm{H}$ ealth and $\mathrm{H}$ usbandry, D epartment of $\mathrm{C}$ linical Veterinary Science, \\ University of B ristol
}

( Received 7 J uly 1997; accepted 30 September 1997; M S. number: SC-1113)

It is gratifying to see in a timely paper, that $M$ ason et al. (1998) concur with many of the concerns we and other workers have raised regarding the methodology and interpretation of consumer demand studies. Their commentary is a useful synopsis of the multifarious problems of this area and includes practical suggestions for solutions which they regard as appropriate for overcoming these.

Some of the comments made by $\mathrm{M}$ ason et al. (1998) are perhaps possible only with the benefit of hindsight. When demand theory was first proposed as a method of measuring motivation, little thought was given to which aspect of behaviour should be considered as the most important. It was implicitly assumed that total duration of a behaviour, or time spent with a resource, would be the best measure. It is only after detailed studies were conducted over several 24-h periods (e.g. Sherwin \& N icol 1996) that it was determined other aspects of behaviour, for example, frequency or regularity, were also important and could be defended even at the expense of duration. Indeed, the rescheduling of behaviour is of considerable interest. I ts occurrence is not necessarily a failing of the methodology, as implied by M ason et al. (1998) in their statement that rescheduling of feeding-bout length does not reflect the importance of feed. $R$ ather, if an animal visits a resource half as frequently as before and makes each visit last twice as long, it is telling us something important. M ason et al. (1998) have already argued that bout length is important and in order to stay twice as long with food, the animal must accept a reduction in its ability to schedule other behaviours optimally. M ethodology in this area is at an

Corresponence: C. M. Sherwin, Division of A nimal $\mathrm{H}$ ealth and $\mathrm{H}$ usbandry, D epartment of Clinical Veterinary Science, L angford House, Langford, BS18 7DU, U.K. early stage of development and we are therefore pleased that M ason et al. (1998) approve of our attempts to assess a variety of methods and measurements.

The four alternative solutions suggested by M ason et al. (1998) as appropriate for measuring behavioural priorities do not overcome all the problems they raise in their commentary. Indeed, three of the four solutions cannot be used to generate demand curves. We discuss these solutions in the order presented by $\mathrm{M}$ ason et al. (1998). It is difficult to see how a method that requires extended bouts of lever-pressing to build up stocks of reward will be valid or practicable. First, training an animal with an accruement method would require a low contingency; we predict this would make training the animal very difficult, perhaps impossible. Second, if an animal was trained conventionally, it would be performing the required operant task (the cost) to carry out a single bout of the desired behaviour according to the reinforcement schedule to which it has been trained: it would not be expecting the contingency to be broken by the experimenter accruing stocks of the reward: this method clearly prevents the animal from scheduling its own behaviour thereby contravening guideline 1 . Moreover, it is likely that breaking the contingency will lead to extinction of the response. This problem also relates to guideline 3 which suggests that the price paid and the amount of resource used must co-vary. We do not believe it is always possible to set up a system that allows the price paid and amount consumed to co-vary in the way required to measure elasticity of demand as suggested by Mason et al. (1998). Consider a behaviour in which satiety is achieved only at the end of a single bout, and the animal will work repeatedly only when it can complete the bout to achieve satiety (possible examples include mating, 